\title{
Shifting the discourse from survive to thrive: a qualitative exploration of beliefs, actions and priorities for early childhood development in Uganda
}

\author{
Daniel Strachan ${ }^{1}$ Lydia Kabwijamu², Monica Okuga², \\ Callie Daniels-Howell ${ }^{1}$, Hassan Haghparast-Bidgoli ${ }^{1}$, \\ Rebecca Nantanda ${ }^{2,3}$, Jolene Skordis ${ }^{1}$ and Peter Waiswa ${ }^{2}$
}

Abstract: Investment in early childhood produces healthier and more productive adults, benefiting families, communities and countries. Carers need support in providing nurturing care, but there is little information on what is required to achieve acceptable, affordable and effective early childhood development (ECD) in resource-constrained environments. Uganda has identified human capital development as a key priority. In Uganda, an estimated 75-80 per cent of 3-6-year-olds have no toys and are not engaged in learning. Uganda has established a national Secretariat to support ECD and there is political will to define a multi-sectoral programme with low resource requirements. This study aimed to understand the characteristics of an acceptable, scalable and effective ECD intervention in Uganda. This study finds the discourse around ECD has not yet moved from 'survive' to 'thrive,' with nutrition and child health programming such as immunisation widely conflated with ECD. Intelligence is seen as innate, with carers believing they have little influence over cognitive development. Language and beliefs around child stimulation will need to be carefully constructed, given the significant and persistent negative impact of poverty and malnutrition on both child survival and the potential for child stimulation in this context.

Keywords: Early childhood development, parenting, child stimulation, cognition, Uganda, peer coaching, nutrition.

(C) The author(s) 2020. This is an open access article licensed under a Creative Commons Attribution-NonCommercial-NoDerivs 4.0 Unported License

${ }^{1}$ UCL Institute for Global Health, London, UK. ${ }^{2}$ Centre for Excellence in Maternal, Newborn and Child Health, Makerere University School of Public Health, Makerere, Uganda. ${ }^{3}$ President, Uganda Paediatrics Association, Kampala, Uganda. 


\section{BACKGROUND}

Early childhood is a critical development phase (Irwin et al. 2007), yet an estimated 250 million children in low- and middle-income countries (LMICs) are at risk of not reaching their developmental potential (Black et al. 2017). Advances in brain research and longitudinal studies have demonstrated that adverse early experiences have negative effects on brain, language and cognitive development (Black et al. 2017, Luby 2015, Noble et al. 2015, Shonkoff et al. 2012) as well as the crucial attachment and early learning processes that underpin healthy development (Weaver 2014). Poverty, poor nutrition and unstimulating home environments are key risk factors contributing to poor developmental outcomes (Grantham-McGregor et al. 2007, Muhoozi et al. 2016). Intervening early can address these risks and increase future earning potential while lessening the risk of poor physical and mental health (Gertler et al. 2014, Campbell et al. 2014, Walker et al. 2011). Based on an increasingly compelling volume of research evidence, the case for investment in the early years has been made in three Lancet series on Child Development in Developing Countries (2007, 2011 and 2017).

This evidence has led to growing global commitment to intervene at scale in LMICs (Rubio-Codina et al. 2016) and Sustainable Development Goal 4.2 aims to improve access to quality early childhood development (ECD), care and pre-primary education. Trials in a range of settings have provided positive proof-of-concept for high-contact home visits, centre-based care and parenting groups among other strategies (Britto et al. 2018, Yousafzai et al. 2018). However, as Yousafzai et al. (2018) note, few effective ECD interventions have been delivered at scale in LMICs, and fewer have benefitted countries in the sub-Saharan African region. There is also little information on the implementation strategies required to achieve feasible, effective and sustained delivery of ECD interventions (Yousafzai et al. 2018). The potential for impact from early intervention has thus led to an increased focus on the necessary content of ECD interventions (Chan 2013, Lake 2011, Schady 2015) and the need for a clearer understanding of the characteristics of a scalable intervention in low-resource environments. This research agenda becomes more critical given that, in low-income settings, ECD will compete with other Sustainable Development Goal targets for limited funding and other resources.

Uganda is an ODA-eligible' 'least developed country' where children are not reaching their developmental potential. Low levels of psycho-social stimulation are provided to children below 5 years of age (Britto et al. 2013, Muhoozi et al. 2018, Singla et al. 2015) and Britto et al. (2013) report that 75-80 per cent of 3-6-year-olds do not have toys and are not engaged in learning activities. Six interventions have 
already proven effective in improving child developmental indicators in Uganda (Boivin et al. 2013, 2017, Britto et al. 2013, Morris et al. 2012, Muhoozi et al. 2018, Singla et al. 2015). Of these, two targeted preschool or school-aged children (Boivin et al. 2013, Britto et al. 2013), thus missing a critical early life period. The remaining four targeted key affected populations including HIV-positive children (Boivin et al. 2017), displaced families (Morris et al. 2012), impoverished mothers (Muhoozi et al. 2018) and socially disadvantaged families (Singla et al. 2015), and may not be generalisable across the population. Stimulation activities differed across the six studies, but all were high intensity and unlikely to be feasible at scale, targeted vulnerable groups rather than the general population, and none targeted the first year of life. The need to understand what would constitute an effective, affordable and scalable ECD programme for all rural children in Uganda and other low-income settings remains.

This study aims to explore the likely characteristics of an acceptable, scalable and effective ECD intervention in the Ugandan context. To achieve this aim, the study had four specific objectives:

1. To understand the policy landscape that exists to support ECD activities and map current ECD activities.

2. To explore carers' knowledge, attitudes and practices regarding child stimulation and understand their aspirations for children's growth and development.

3. To observe the potential for stimulation in the home or community, including opportunities for children to play and learn and the materials available for use as effective, safe and acceptable toys.

4. To investigate likely opportunities for, and challenges to, the expansion of ECD in Uganda.

5. The findings from this study are presented below, after a description of the study setting and methods used.

\section{STUDY SETTING}

Uganda is an East African country bordered by South Sudan, Kenya, Tanzania, Rwanda and the Democratic Republic of Congo. Uganda has a population of 41.5 million people (World Bank 2017), an average life expectancy of 60 years for men and 65 years for women, according to the World Health Organization, and one of the highest fertility rates globally at 5.8 children per woman (CIA 2017, World Bank 2018). Uganda's economy is largely dependent on rain-fed agriculture and adverse weather conditions have caused average annual GDP growth to slow to 4.5 per cent in the five years to 2016, compared with 7 per cent in the previous period (World Bank 2017). 
While Uganda surpassed the Millennium Development Goal target of halving poverty by 2015 (UBoS 2018), vulnerability to falling back into poverty remains high and the proportion of the population living below the national poverty line rose from 20 per cent to 21 per cent between 2013 and 2017. Addressing this and other challenges, Uganda's second National Development Plan (NDPII) 2015/16-2019/20, aims to support Uganda's progress to middle-income status by 2020. This plan aims to strengthen Uganda's competitiveness for sustainable wealth creation, employment and inclusive growth. The plan prioritises investment in the five areas with the greatest multiplier effect on the economy, one of which is human capital development.

Uganda's government thus sees investment in human capital as central to the country's development and an Education Sector Strategic Plan (ESSP) 2004-2015 was developed to support that policy imperative. The ESSP aimed to address three critical concerns, including the concern that primary schools were failing to provide sufficient literacy, numeracy and life skills (MoES 2010). While the ESSP focuses on the creation of quality schooling environments and training teachers, the challenge of achieving a sufficient standard of primary schooling may begin before children start at school. Just 37 per cent of children aged 36-59 months attend any form of early childhood education in Uganda (UBoS \& ICF 2017) and the majority of pre-school children have no access to stimulating materials at home (Britto et al. 2013, Muhoozi et al. 2018, Singla et al. 2015).

National commitment to improving ECD is multi-sectoral in Uganda, reaching beyond the education sector. This is exemplified by the establishment of The National Integrated Early Childhood Development Policy (NIECD) Secretariat at the Ministry of Gender, Labour and Social Development (MoGLSD). The Secretariat also includes the Ministries of Health and Education. The Secretariat developed and disseminated an integrated national ECD policy (MoGLSD 2016a) and policy action plan (MoGLSD 2016b). The policy emphasises multi-sectoral and disciplinary collaboration at all levels of government with a focus on supporting families to create an enabling environment for a child to develop and thrive (see Box 1 for key elements of the policy). The policy action plan sought to improve ECD outcomes through a new cadre of community health extension workers (CHEWs), thus formally rolling out ECD activities through the health sector. Uganda's health system operates at tiered levels with the village-based village health teams (VHTs) at the first, that is community, level, and the national referral hospital (Mulago) the last (seventh) level. VHT members are volunteers, resident within the communities to whom they minister services. They provide health promotion, health education, treatment and referral for malaria for children below 5 years of age but also for diarrhoea and pneumonia, collectively known as integrated community case management (iCCM) (MoH 2010a). The introduction of a new cadre of health extension workers was to complement the 
Box 1. Key features of Uganda's national ECD policy.

The policy is 'anchored within' international frameworks including the United Nations Convention on the Rights of Children (United Nations 1989), the UN Sustainable Development Goals and the UN Convention on the Rights of Persons with Disability (United Nations 2006).

Vision: All children in Uganda from conception to 8 years of age grow and develop to their full potential.

Mission: To ensure equitable access to quality and relevant ECD services for holistic development of all children from conception to 8 years.

Goal: The major goal of the policy is to provide direction and guidance to all sectors for quality, inclusive, coordinated and well-funded ECD services and programmes.

\section{Objectives:}

1. To harmonise existing ECD policy related goals, objectives, strategies and initiatives within and across all sectors.

2. To set, improve and align standards for ensuring access to well-coordinated, quality, equitable and inclusive ECD services within and across sectors.

3. To build and strengthen capacity of systems and structures to deliver integrated quality and inclusive ECD programmes.

\section{Guiding principles:}

- Focus on holistic development of the child incorporating physical, mental, social, emotional and linguistic domains while recognises they are interwoven.

- Promote access to services equitably and does not discriminate by gender, geography, location, race or tribe.

- Should be flexible, inclusive and adaptive to local, contextual needs related to children living with HIV/AIDS, disability, in conflict situations or who are homeless.

- Families, parents and caregivers have the primary mandate for the care and upbringing of young children. ECD services should engage with and empower families in the care and development of their children.

- Leadership and accountability of ECD shall be shared across sectors.

- The Ugandan government's commitment to the UNCRC constitutionally mandates ECD as a right.

- Public private partnerships are central to the delivery of ECD programmes with all levels of government, community, local leadership and parents/carers to be involved.

- Programmes should focus on the continuum of care from conception to age 8 years.

\section{Main focus areas:}

1. Early childhood care and education-focus on all ages and equitable access to quality care and developmentally appropriate early learning and stimulation opportunities.

2. Food security and nutrition-focus on community mobilisation for adoption of health nutrition behaviours. 
3. Child protection.

4. Primary healthcare, sanitation and environment - 'The main thrust for this will be prioritising stimulation, care and development aspects in the traditional child health and survival programmes to ensure children not only survive but also thrive.'

5. Family strengthening and support.

6. Communication, advocacy and resource mobilisation-focus on equitable service delivery and engagement with stakeholders at all levels.

7. Multi-sectoral partnerships and coordination-focus on cross-disciplinary and sectoral partnerships and collaboration.

VHT cadre, but this strategy was abandoned in 2018 due to cost concerns (Namuli 2019). However, the political will to support ECD through multi-sectoral activities remains.

Our study was based in Luuka district, Eastern Uganda. The district comprises 43 parishes and 281 villages, with a population of 262,100 people. Luuka has a population growth rate of 2.1 per cent, a fertility rate of 7.3 per woman and anerage household size of 5.4. The district has a young population, with 17.7 per cent $(42,129)$ aged between 0 and 4 years (UBoS 2016). The provision of basic health and social services is the responsibility of the Ugandan government and its development partners, through the district health and social service delivery mechanism. According to the NIECD Secretariat Annual Report 2016, the traditional leader (the Kyabazinga) of Busoga had endorsed the NIECD policy and pledged to advocate for positive ECD practices in his kingdom.

\section{METHODS}

In-depth interviews (IDIs) and focus group discussions (FGDs) were conducted with carers, including mothers, fathers and grandmothers, antenatal clinic nurses, VHT volunteers, opinion leaders such as imams and priests, and policy stakeholders at national and district level. Two interviews with policy stakeholders were conducted in Kampala and one in Jinja, while the remaining interviews and group discussions took place in Luuka District.

Five fieldworkers fluent in the most common language in Luuka District, Lusoga, as well as Luganda and English, were recruited and trained. Training explained the background to the research, the content of the topic guides and how to use them, data collection processes and standards, recording and documenting interviews and group discussions, the principle of informed consent and the participant consent process, 
and the data collection schedule. Topic guides were translated into Lusoga and Luganda by Makerere research staff and fieldworkers and back translated to English to assess accuracy.

\subsection{Sampling and recruitment}

Local leaders were consulted before commencing with recruitment to ensure that all activities had local approval. Purposive recruitment of research participants was then conducted by community informants. Recruitment aimed to garner diverse perspectives from a range of carers with at least one child or grandchild under the age of 1 year. Similarly, nurses and VHT volunteers with differing experience levels were invited to participate, as were policy stakeholders with a range of roles and responsibilities for health, education or welfare.

Individual informed consent was sought from each participant in their preferred language, after they had been provided with a briefing on the project, the voluntary nature of their participation and how their data would be managed. Each participant was provided with a project information sheet. Participants were asked to consent to being sound recorded, for their data to be securely stored and transported to the UK, and for their de-identified testimony to appear in academic reports and peer-reviewed journal articles.

Respondent characteristics, the number of respondents and the content of different research encounters are detailed in Table 1.

\subsection{Data collection, recording and analysis}

Pre-tested topic guides were developed by the research team based on the research aim and objectives. Interviews and group discussions were then facilitated by trained fieldworkers using the topic guides, and ranged in duration from 45 to 120 minutes. All research encounters were audio recorded. The recordings were then transcribed into English from the original Lusoga, Luganda or English by the fieldworker who conducted the interview. Daily feedback was provided to fieldworkers during debriefing sessions led by DS, MO and RN. The debriefing provided a forum for the research team to review and refine topic guides, trouble shoot methodological challenges and conduct initial, collaborative identification of themes within the generated data.

IDI and FGD transcripts were analysed thematically, using an iterative, inductivedeductive approach called analytical induction (Braun \& Clarke 2006). The original topic guides helped structure the thematic analysis, but scope remained for data to be generated in unanticipated content areas and for themes to emerge from the data 
Table 1. Methods, respondents and content for each research encounter.

\section{Method}

IDI Respondents

12 Mothers, each with an average of 4 children

8 Antenatal care nurses

10 Village Health Team volunteers

FGD 10 Policy stakeholders and opinion leaders including representatives from; the Ministry of Gender, Labour and Social Development (1), the Ministry of Education and Sports (1), a district health officer (1), an assistant district health officer (1), a district ECD focal person (1), the Assistant Secretary acting for the Chief Administrative Officer (1) in Luuka District, an ECD-focused NGO operating in Luuka District (1), an imam (1) and a priest (1) from Luuka District, and a representative from RHITES-EC ${ }^{2}(1)$.

2 Groups of mothers, each with 7 participants

2 Groups of grandmothers, with 6 participants in the first group and 7 participants in the second 2 Groups of fathers, each with 6 participants

\section{Content}

1. Knowledge, attitudes and practices regarding child stimulation.

2. Aspirations for children's growth and development.

3. Opportunities for stimulation in the home or community.

4. Current ECD activities.

1. Current ECD policy and activities.

2. The potential for additional ECD activities.

3. Which systems would be best placed to deliver future activities.

4. The opportunities and challenges for current and future ECD activities.
1. Knowledge, attitudes and practices regarding child stimulation.

2. Aspirations for children's growth and development.

3. Opportunities and challenges for ECD implementation.

(Braun \& Clarke 2006). Provision was made to recruit additional respondents in the event that data saturation was not reached, but this was not necessary. When multiple examples of each theme were identified during the daily debrief meetings the decision that data saturation had been reached was taken and additional research encounters deemed unnecessary. The daily debrief was a key strategy used to mitigate the risk of inappropriately interpreting the findings.

${ }^{2}$ The USAID-funded Regional Health Integration to Enhance Services in East Central Uganda project (USAID RHITES EC) aims to improve the quality, access and utilisation of health care services through an integrated service delivery approach. https://www.urc-chs.com/projects/rhites-ec (accessed 10 May 2019). 
The field team was co-led by Ugandan and UK-based researchers. Perspectives of all team members were solicited to triangulate interpretations of data meaning.

\subsection{Ethics}

The proposal and all project tools were approved by the Makerere University School of Public Health Higher Degrees Research and Ethics Committee (MakSPH-HDREC approval number 572) and the University College London research ethics committee (project ethics identification number 12565/001). The research team also obtained permission from the Luuka District Health Officer, and from the 'in-charges' of health facilities visited. Written informed consent was obtained from each participant in the study.

\section{RESULTS}

The results address the objectives of the study in three main sections: First, the policy landscape and current activities are described (Objective 1). Second, carer knowledge, attitudes and practices regarding child stimulation are explored, along with carer aspirations for children and the potential for child stimulation in the home or community (Objectives 2 and 3). Finally, likely opportunities for, and challenges to, the expansion of ECD in Uganda are described (Objective 4).

\subsection{The ECD policy and activity landscape in Uganda}

As described in Section 3, policy stakeholders, opinion leaders, nurses and VHT members were asked about current ECD policy and activities either nationally or in the community.

Awareness of current ECD policies and activities differed by the hierarchical level and mandate of respondents. National-level representatives from the Ministries of Gender Labour and Social Development (MoGLSD), Education and Sports (MoES), and Health $(\mathrm{MoH})$ were concerned with policy formulation, coordination of activities and monitoring and oversight. While at the sub-national level, policy stakeholders were concerned with advocacy for ECD and the delivery of programmes with an ECD component or focus.

we are responsible for developing policies and these guidelines and operational standards. The government has supported us in that, even creating advocacy, we are carrying out seminars in the various districts to advocate for ECD.

IDI stakeholder MoES 
Stakeholders at both national and district levels tended, however, to emphasise the importance of nutrition or health interventions when discussing child development priorities. Only one policy stakeholder mentioned child stimulation or activities focused on cognitive development. None opposed cognitive development, but the majority did not describe any associated ongoing activities, articulate the value of such activities or what they entailed outside of maternal or primary school education. ECD appeared either to be categorised as a lesser priority than improving health and nutrition, or to be equated with improving health and nutrition:

you can't talk of a child being polite, you can't do another thing when a child has nothing to eat.

Policy stakeholder

At the health facility level, according to the majority of respondents, ECD is integrated into reproductive, maternal, newborn and child health service provision. Policy stakeholders and nurses described delivering ECD through health education talks for pregnant mothers and in young child clinics, encouraging the use of antenatal care and child health services like immunisation. Respondents further described how ECD communication was highly nutrition focused, with facility-based health workers conducting nutritional assessments for children. During postnatal care and young child clinics, presenting children are assessed for malnutrition or any other illness and treated or referred depending on the condition and this is seen as 'child development'.

Child development begins during pregnancy thus in antenatal we assess these mothers for nutrition, educate them about feeding ... then during labour you still encourage this mother to take feeds immediately after delivery we initiate breastfeeding within the first hour which is a key in child development then we also continue emphasising it during postnatal, we encourage immunisation after birth.

IDI antenatal clinic nurse (ANC) nurse

Policy stakeholders also described ECD projects which focused on promoting household food security, post-harvest handling of food and improving nutrition practices.

In Luuka district we are implementing a model pioneered by USAID and UN World Food Programme. This model is looking at improving food security at household levels and we look at how we can empower households in these communities to improve on their food security. In so doing we promote good agronomic practices, those are practices which help households to improve on yields.

District-level policy stakeholder

At the community level, VHTs were described as conducting ECD activities that included breastfeeding education, nutrition support and growth monitoring. 
In short, while the formal national ECD policy was known, or known of, by many national-level policy stakeholders, no policy stakeholder, opinion leader, nurse or VHT worker interviewed for this study, described activities related directly to child stimulation or cognitive development.

\subsection{Carer knowledge, attitudes, practices and aspirations}

This conflation of ECD with nutrition and physical growth was reflected again in responses from carers while exploring their knowledge, attitude and practices with respect to ECD. Similarly, their aspirations for children focus on physical growth, while the opportunities for stimulating play are limited by the time-consuming activities needed to survive in an agrarian economy. Each of these results are explored in more detail below, drawing on responses from mothers, fathers, grandmothers, VHTs and nurses.

\subsubsection{Knowledge, attitudes and practices}

i) Child development is growth, survival and love

When discussing child development, all carers largely focused on physical health and needs including adequate nutrition, the provision of shelter, enabling quality sleep and ensuring children are fully vaccinated. Carers want their children to be physically healthy, describing distress and frustration when they fell ill.

A small number of respondents made a weak link between nutrition and brain development, while a larger number of respondents emphasised the importance of showing love to children.

A healthy child should eat well, breast feed well and play well because such things help a child to develop well ... and also if he sleeps well with good beddings to cover him. ... If a child is feeding on cold food the brain will be weak and will not develop mentally well and also if the child also feeds on only one type of food like cassava alone the brain will not be excited

FGD mother

Love is the most important. If you show love, s/he grows well. Will not fear you. A kid will feel good all the time. You easily play with the child. Because of the love exhibited, even when sick, a child will still be jolly.

FGD mother

Indeed, some VHTs identified interactive play as a means through which carers show love for their children, but noted that few carers engaged with children in this way. Moreover, they indicated it was women who played this role, suggesting that fathers were less likely to play with a child. 
There are some women that play with the children because some of them when we tell them about love and care for the children, they take it seriously. There are others that will not take it seriously and they may not play with the children as they will understand things differently.

VHT IDI

ii) Grandmothers explained that learning started at home

Grandmothers identified a role for carers in child learning. Within the group discussions all grandmothers suggested that, apart from mimicking other children, learning started in the home and with a child's primary carers. They explained that learning and development occurred through interactions between children and their carers, such as when asking a child to fetch something. While they primarily highlighted teaching functional motor skills and the good manners described later, one grandmother also highlighted the importance of talking to children for the development of language.

It is you the care take who has to teach the child, for example you will start to tell the child that you go and bring for me that mug, and the child will go and bring it, you go and bring the sauce pan and the child will go and bring it, then you will send the child to go and bring the kettle, and it will bring it.

FGD grandmother

\subsubsection{Aspirations for children}

i) Intelligence is important but cannot be shaped by parents

Despite a primary focus on children's physical development, carers also express a desire for their children to be intelligent. Intelligence was, however, most commonly felt to be 'god-given' or innate. Only a minority of respondents indicated that intelligence might be developed by parental modelling of desirable actions or encouraging play with a variety of toys.

Some children are born when naturally they are not going to be intelligent however much you feed them. Such children have their brain weak like that forever they will never be intelligent.

FGD mother

For a child to be intelligent you allow him to play with different toys... buy different things that make noise [the rattles] that make the noise and the child will feel excited and become intelligent.

FGD mother

When VHTs were asked what makes a child intelligent, they described adequate nutrition and meeting a child's basic physical needs. When asked how they would know if a child was intelligent, several VHTs described a child who was physically 
strong and seldom ill, who was able to meet physical developmental milestones on schedule, and who could verbally communicate.

So when you give the child this breast milk it will help the child to grow healthy and intelligent and when the child reach the age of eating solid food you have to feed the child with balanced diet, this will make the child very healthy and intelligent.

IDI VHT

Some VHTs did suggest that care and guidance were important but this was usually accompanied by emphasis on the importance of physical development and health.

What makes this child intelligent is all about the care you give the child or the behaviour you put in this child as long as s/he is feeding well and his/her body is happy not falling sick you always know what is happening to the child and you take to the health centre for medication.

IDI VHT

ii) The importance of good manners and discipline

Carers placed strong emphasis on the good behaviour and manners of children. Children respecting elders, greeting and serving visitors and helping carers without resistance were desirable attributes and promoting children's capacity to demonstrate these traits was a priority.

When you have good manners, you are trusted and people will welcome you always and you will never lack.

IDI mother

The objective of good manners was commonly described with reference to the carer's relationships with the community. Carers commonly described negative behaviour as due to a carer's lifestyle choices and stressed the need to raise your child well in order to maintain a positive community image.

When I am with my child and he is growing well and has good manners it gives me respect from other people of the community because of those good manners.

FGD mother

Carers explained that young children are taught appropriate behaviour by carrying out small errands and being disciplined when they do not adequately perform them. At a young age, girls are taught to assist mothers with chores and in fulfilling household responsibilities, with boys and girls both expected to care for other young children. The parental role in instilling desired behaviours was highlighted.

Good behaviours start with the parent, you keep telling him what to do and he learns with continuous telling him.

IDI carer 
All carers discussed disciplining with corporal punishment. Most carers described beginning by the age of 1 or 2 years. Grandmothers and fathers shared the same positive views of such punishment although among grandmothers it was more pronounced, with some suggesting that physical punishment was critical in deterring the child from inappropriate behaviour.

You tell them not to spoil water and you find them to have done it and many other things so I cane them because they are annoying and so they learn and grow up knowing it.

IDI carer

\subsubsection{The potential for child stimulation in the home or community}

The responses highlight how carer-child interactions must fit in around daily chores and responsibilities. Most carers, VHTs and nurses described infant feeding in relation to the carers' work schedule, particularly those who are subsistence farmerscolloquially known as those who 'dig'. Commonly infants either accompany mothers to work or are cared for by other young children while carers complete their work.

While carers all claimed that they did play with their children, the results suggest this is not structured play, is of short duration, may not be highly stimulating and is predominantly initiated by the child. Children largely interact with other children.

you can't say I have this time for playing with my kid ...; now let me say me, who works if I break for lunch I go home and play with my kid for like ten to twenty minutes.... For those who stay at home the mother can play with the baby while preparing food, at the time of breastfeeding then when she is feeding food and the baby is not breastfeeding at the time of sleeping when the baby wants to sleep. You do the household chores while playing and attending to your child, if the child wants something you give as you are talking, as you are doing the chores.

IDI nurse

The results point to a near universal belief that play is for its own sake. Few respondents suggested that play contributed to social or cognitive development, although some described play as teaching basic skills like sitting, walking or following commands. A minority focused on play as providing happiness, which they saw as important for child development.

If you play with the child this will prove to this child that you love the child and the child will be happy and the happiness will make this child grow well and will make the child healthy and intelligent, compared to a child who is neglected by the parents whose will always be miserable, a child's playing make the child grow well because the child will always be happy.

IDI VHT 
Nearly all carers reported that they hadn't bought toys or provided access to picture books. However, during the FGDs several mothers explained that they tell traditional stories and riddles and sing traditional songs. Others explained that dolls, balls and rattles were locally made out of available materials (often banana fibres) and provided to young children.

I remember my mother used to sing for me and therefore I also sing for my children and tell them poems, riddles.

FGD mother

According to nurses, fathers seldom had time for interaction with their children and such interaction was only possible among the few who stayed at home. Fathers in the FGDs strongly advocated for the importance of nurturing care for children, but it was unclear whether they delivered this care themselves. It was suggested by all mothers interviewed that they did not.

The most important is to show and tell their children that they are loved then the rest can follow.

FGD father

The only instance where carers viewed play as learning was when girls pretended to cook and carry children. This was seen as good preparation for future responsibilities. Most carers described a gender difference in play, with boys described as playing football and games, while girls played games that mimicked female roles. Girls were seen as sharper than boys because they learn communication and responsibility more quickly as they assist carers in the kitchen and when caring for young children.

Boys should have different toys because girls have their own games and boys too. Boys like football ... running but also girls can do that but girls like playing like delivering babies, cooking.

IDI mother

This suggests that girls may be exposed to greater carer interaction in the study context because of the time they spend with mothers while cooking, cleaning and looking after children. This is in contrast to boys who, according to respondent testimony, more commonly play on their own or with other children.

4.3 Opportunities for, and challenges to, the expansion of early childhood development in Uganda

The opportunities for expanding ECD activities in Uganda, and the likely challenges to effective expansion, were explored with all respondents. 


\subsubsection{Opportunities for the expansion of effective ECD activities}

i) Village health teams are already in place

Policy stakeholders strongly identified the potential for VHTs to be more engaged in implementing ECD activities, given their close contact with families. Nurses were described as providing health education at the facility level, while at the community level, VHTs already engage with young children and families and are trusted.

as they are doing those other activities they do of home visiting they [VHTs] are able also to identify babies who need special care and also as they do home visiting they also continue to talk to caretakers on breastfeeding all these babies under the two years. They encourage mothers to exclusively breast [feed] until 6 months.

District-level policy stakeholder

However, despite their multifaceted roles, VHTs are described as lacking ECD knowledge and it was suggested that they would benefit from ECD-focused training and mentorship.

They [VHTs] are doing something but not in relation to early childhood development, like they have been identifying children who need referral to the facility and refer to the health facility, children with danger signs ... in regard to early childhood development they haven't been oriented on how that programme runs.

Policy stakeholder

Stakeholders noted the high level of esteem in which VHTs are held within the community and strongly advocated for them to play a role in any ECD-focused activities.

ii) Mobilise local opinion leaders

Policy stakeholders also suggested that any services provided by VHTs could be usefully complemented by ECD communication from locally trusted religious leaders, who are often themselves parents. These opinion leaders are already commonly used to support local health campaigns, including mass immunisation campaigns. Stakeholders suggested that collaboration with these local leaders represented an opportunity for more collaborative and effective ECD communication in the community.

the health workers first come to us the religious leaders and ask us to mobilise for them, and they know that on Friday women come in big numbers in the mosque so they take an advantage of this day and we also announce it in the mosque and all women go direct for immunisation after prayers.

Religious leader 
to me, churches play a very big role in transforming the lives you know it is part of saving the soul, and it depends on how well the leader or the imam packages his statement.

District-level policy stakeholder

iii) Multi-sectoral collaboration is key

Stakeholders across ministries and from NGOs (non-governmental organisations) emphasised the need for ongoing linkages, collaboration and communication between programmes, organisations and sectors. They saw this as an important opportunity for ECD programming, given the apparent will for positive change. One stakeholder from the Ministry of Education also articulated the need for collaboration within the government, aware that a chain of awareness and communication is needed from policy makers to those directly implementing policy if ECD activities are to be implemented effectively with the desired impact.

so we are doing this to ensure that at least we are able to reach the ground so that the services can benefit the final beneficiary who is the child, because without doing that, you can't sit at the ministry and expect each and every idea to move down, you have to work in collaboration of all the communities.

IDI stakeholders

One stakeholder articulated the need for NGOs to collaborate closely with district officials in order to build capacity, so the services they currently offer might in due course be successfully handed over to the public service. One such way they aim to do this is through holding quarterly forums for CSOs (civil society organisations) to come together, share what they are doing, and determine how they can support one another.

what we are doing as RHITES [Regional Health Integration to Enhance Services in Eastern Uganda] is to capacity build the district government people to work with us just that in case RHITES goes away the district can take away the programme, and that is a key component and the emphasis is really put on it, because if you want your programmes to take off the district people have to work with you.

IDI stakeholder

iv) Ensure that national ideas translate into local priorities

In addition to collaboration with district and sub-county leadership at the strategic level, many stakeholders mentioned the importance of including local leaders in discussions around implementation. Engaging such leaders, including government officials, religious leaders and local chiefs, was considered essential in particular for effective training and monitoring of VHTs, follow-up with families, and the reinforcement and legitimisation of information. 
But as you engage the VHTs at that level you need in one way or the other to involve let us say the sub-county leadership to give it more weight, though the VHTs can do the work but if they are backed up by the sub-county leaders it will be a lot stronger and it will achieve results.

IDI policy stakeholder

\subsubsection{Challenges to the expansion of effective ECD activities}

i) Low levels of knowledge and awareness

Nurses reported a general lack of adequate knowledge and skills in ECD. Poor parental knowledge in particular, was cited by many as a constraint to better ECD outcomes. For instance, nurses frequently mentioned parents' lack of knowledge regarding appropriate feeding practices after weaning as a contributor to malnutrition at community level. According to nurses, parents had food but did not know what food to give their children as part of a healthy and balanced diet.

The common causes of malnutrition actually it is just lack of knowledge ... yes, lack of knowledge of what to give their children. They have the feeds but they don't know what to give to their children.

IDI nurse

This contrasted somewhat with the testimony of the carers themselves and that of VHTs described later in this section. In the FGDs, carers reported awareness of the need for balance in diet.

When you are pregnant they advise you to eat energy-giving foods like vitamins and proteins like eggs, dodo [greens], cabbages you take the soup and your boost your haemoglobin levels.

FGD mother

VHTs cited food shortages as a critical challenge to child development, as described later in this section.

ii) Carers are time poor

A key challenge to improved ECD is the competing demands on carer time. VHT descriptions of carers struggling to balance all of their responsibilities and finding time for their children echoed carer testimony. A carers' many responsibilities take up the majority of their day, with very little time left to spend focused on children.

Mothers give less time to their children, you find the mother busy in goats, pigs and cows, so you find the only time the mother has is when breast feeding the child.

IDI VHT 
iii) The role of fathers - a potential opportunity?

Respondents describe fathers as playing almost no role in ECD, despite being the main household decision maker. Usually, the practical role they played was limited to the provision of financial support, with little involvement in play or stimulation. This situation was justified by nurses and VHTs, who suggested that the primary role of the father was to 'provide', while the primary role for the mother was to 'care'.

Most of the men don't know what they are supposed to do at home or what they are supposed to provide to women to support their children at home.

IDI nurse

During FGDs with mothers, discussion centred on the lack of fathers' ability when providing for the needs of children. At the same time, this was often tempered by an emphasis on the love between babies and fathers-and the importance of children being familiar with both parents.

The child feels happy when playing with the father, even when the mother goes somewhere when the child is used to the father the child will not get problems so when the child is only used to the mother when you leave the child with the father this child will have hard time because helshe is not used to the father, and by the time you come back the child will have even fallen sick.

FGD mother

iv) Poverty and food insecurity

Severe acute malnutrition among children was described as common in the community. When probed further, policy stakeholders and VHTs attributed malnutrition to persistent food insecurity. They described the role of sugarcane companies in leasing or purchasing land and growing cash crops rather than food crops. In areas where other food crops are grown, they tend to be sold off for money at the expense of family members' diet. This creates a critical food shortage and poor dietary intake resulting in malnutrition.

These days people grow sugarcane for sale and there is not enough land for growing food for home consumption.

VHT member

Poor nutrition is compounded by other conditions of poverty according to respondents. Nurses describe how poverty impedes access to care. Sometimes carers do not seek care because they cannot afford the transport when they are referred.

The finance is not there now ... at home to support these babies like feeding, clothing, long distances from the villages ... to the health centres. 
v) Lack of perceived support for frontline workers

Challenges were also identified related to support for health workers; in particular, in terms of appropriate demonstration materials and incentives for them to perform as required. Three ANC nurses reported that, often when providing what they described as ECD information, they lacked visual materials to aid their presentation and, in their view, the traction of their communication was lost.

We lack these things to demonstrate to the mothers when we are health educating them, and we don't have money, to make these mothers know that I am supposed to do this and this.

ANC nurse

Several stakeholders noted that VHTs provide services in a voluntary capacity and their VHT activities take them away from paid work. They suggested that long working hours and covering long distances to reach community members adversely affected their work and income. Stakeholders further suggested that more reliable support supervision, refresher trainings and the provision of resources such as transport could assist VHTs.

They need to get knowledge through refresher trainings or those workshops.

District policy stakeholder

They move in the whole village without transport, but you are moving and you have to reach these people but you don't have a bicycle, and this is a very big challenge, and they are also saying that they are not given any incentive they expect them to do voluntary work but that voluntarism is dying off slowly, they also don't want to work for free, they are de-motivated.

District policy stakeholder

\section{DISCUSSION}

This study aimed to explore the likely characteristics of an acceptable, scalable and effective ECD intervention in Uganda. To achieve this aim, the study had four specific objectives. The first objective was to understand the policy landscape that exists to support ECD activities and map current activities in Uganda. The early years are a critical and now well-recognised period for intervention when seeking to positively influence health and development outcomes through the life course (GranthamMcGregor et al. 2007, 2014). This period spans the antenatal period through to school entry. In terms of access points for public sector services, opportunities exist for intervention by the health, education and social services sectors among others. Uganda 
has recognised this shared responsibility by establishing a National Integrated ECD Policy and Action Plan to be overseen by The National Integrated Early Childhood Development Policy (NIECD) secretariat (MoGLSD 2016a, 2016b). The findings of this study indicate that there is strong political will to support ECD at all levels, but while national policy makers understand the policy imperative and the national plan, there may be weaker translation of policy into district and community-level activities. At these levels, ECD activities are equated only with health and nutrition activities, with little emphasis on child stimulation or the importance of cognitive development. This contrasts with the emphasis of the NIECD (see Box 1) and the body of evidence widely advocated in the scientific literature in support of creating high-quality ECD environments described briefly in the introduction section of this paper and exemplified by the three Lancet series on Child Development in Developing Countries (2007, 2011 and 2017). This lack of local emphasis on child stimulation and the importance of cognitive development constitutes both a challenge and an opportunity:

- Moving the narrative from health and survival, to stimulation and thriving in accordance with the NIECD policy will be a challenge - particularly if we are to avoid setting up competing agendas.

- However, the lack of a 'stimulation programme' suggests an opportunity for positive impact which has not yet been exploited in this context.

The second objective of this study was to explore carers' knowledge, attitudes and practices regarding child stimulation and to understand their aspirations for children's growth and development. Carers' responses reflected those of policy stakeholders, opinion leaders, nurses and VHTs in the primacy given to physical health and nutrition as 'ECD'. The findings of this study suggest that parents are focused on the physical development of their children and that they see the achievement of this as mostly contingent upon their capacity to provide shelter, nutrition and treatment for their child when they are ill. Respondents felt that normal development should follow if these foundations are provided. Intellect and cognitive development were largely viewed as innate and beyond the influence of carers. Carers did, however, explain the importance of showing love to support child growth, happiness and possibly also development, but simultaneously and almost universally praised the use of corporal punishment in eliciting compliant behaviour from children. Play was not seen as stimulating but simply something that children do to remain occupied and happy. Future studies should aim to understand what language could be used to describe stimulating play in such a way that parents will believe in the importance of their involvement and their efficacy as change agents for ECD.

Carers in our study aspire for their child to behave well and be well mannered. They see the willingness to greet strangers and attend to their needs as well as fulfil domestic 
chores as indicative of such traits. These characteristics were considered to be on public display and critical to the wider social standing of the family. That is, the views of neighbours and community members matter and the esteem their child and, by association, the carer is held in is important. Respondents also noted that they reference the approach of parental peers and even incorporate witnessed parenting practice into their own approach when they view it as positive. In this and other comparable settings, we thus advocate for an approach based on peer influence and wider community engagement. A focus on influencing social norms around child interaction would be needed.

The Saturation+ approach to behaviour change implemented by Joanne Murray and colleagues in Burkina Faso may represent a useful model to guide such an approach. Murray and colleagues propose repeated exposure (that is, saturation), the use of locally resonating stories and an evidence-based strategy (that is, science) to influence social norms. The principle is that stories have a dramatic hook or narrative that resonates with those targeted for influence and that key messages are absorbed, communicated and confirmed by other, complementary, messaging they are exposed to (Murray et al. 2015). The Saturation+ strategy has been used within a mass media campaign, although it could potentially be adapted to a community-based model in the Ugandan context, possibly led by VHTs, as explained later in this section.

As noted in the introduction, previous ECD interventions in Uganda targeted older children or vulnerable groups and were delivered at high intensity. This pattern is echoed regionally (in East and Southern Africa) where ECD-focused interventions commonly focused on nutrition while measuring development outcomes (Manji et al. 2014, Prado et al. 2017, Stewart et al. 2018), utilised parenting programmes for stimulation but were targeted to vulnerable groups such as children living with foster families (Worku et al. 2018) or were delivered at high intensity through home visits (Wallander et al. 2014, Worku et al. 2018). Two studies nevertheless have particular resonance for what may be effective in the Ugandan context. Worku et al. (2018) advocate integration of ECD strategies into existing services based on their work in Ethiopia, while a programme in Zambia initiated fortnightly, parent-led groups recruited from home visits with a curriculum based on WHO's Care for Development package (WHO 2012) that had a significant impact on stunting and child language development (Rockers et al. 2018). Adopting the Saturation+ strategy may enable the development of an effective strategy that can be delivered at a lower intensity (that is, less frequently than fortnightly) and that is, as a result, scalable. In so doing it may also positively influence the development of children more broadly, across development domains (that is, cognitive, motor-skills and social emotional development in addition to language) and including those living in diverse circumstances. It may have impact through the life course and enable intervention at multiple stages from conception to age 8 years in accordance with the inclusion priorities of the NIECD (see Box 1). 
The third objective of this study was to observe the potential for stimulation in the home or community, including opportunities for children to play and learn and the materials available for use as effective, safe and acceptable toys. This study found few opportunities for consciously stimulating activities, as families are both time and resource poor. Links between play and stimulation are also poorly understood. Practical approaches for incorporating stimulating activities and communication with children into busy daily lives may be advocated for and modelled by respected opinion leaders and peers. To achieve this, we propose three additional emphases for carers building on the Saturation+ approach. We call this Saturation++ and the additional emphases are as follows:

1. Self-efficacy or 'you can do it' - emphasis here is on influencing carers' belief that through carer actions a child can achieve valued developmental and life outcomes. This emphasis draws on the social cognition theories of self-efficacy (that is, repositioning beliefs around the cause of change and the belief that they can enact this change) and outcome expectancy (that is, the notion that if they commit to a course of action a valued outcome may be achieved) (Bandura 2001).

2. Steps and skills or 'how to do it' - emphasis here is on carers' understanding the child stimulation and nutrition actions they can take to achieve valued outcomes for their child and how they can incorporate these actions into their daily lives. The key here is that this content is delivered and modelled by peers. This emphasis draws on theories of social norms, modelled behaviours, social identity and coaching (Chung \& Rimal 2016, Haslam et al. 2010). We also note the positive impact of previously implemented peer-led parenting groups in Uganda (Singla et al. 2015).

3. Second nature or 'everyone is doing it'-emphasis here is on the recommended actions being commonplace and normal. This again draws on social identity theory where the normalised actions of a collective one feels a member of are more easily adopted and routinely practised (Postmes \& Branscombe 2010).

It is important to note that most study respondents noted the influence of poverty on child development in Luuka. Indeed, the pervasive impact of poverty cut across the findings. While there is evidence for the protective influence of psycho-social stimulation on child development (Walker et al. 2011), it will be important for any programme to be respectful of local priorities if advocating for change. Important local challenges, such as the influence of the sugarcane companies, were also noted by respondents. Engaging with such priorities and building a locally appropriate strategy is, we suggest, most likely to be achieved through a community-led approach.

The final objective of this study was to understand the likely opportunities for, and challenges to, the expansion of ECD activities in this context. When describing 
likely challenges, respondents described a lack of knowledge and awareness, carers being time poor and fathers' traditional role as provider of resources but not care. Poverty and food insecurity may also undermine stimulation efforts at the household level, as previously discussed, but also at the systems level if there is a perceived lack of support for frontline workers and VHTs working as volunteers rather than paid staff.

Conversely, findings from all respondents highlighted five potential opportunities for the expansion of effective ECD activities in Uganda; i) There is an opportunity to help parents understand the significance of stimulating activities; ii) VHTs are already in place as trusted and respected members of the community, with close links to families and their young children; iii) local opinion leaders are willing to be mobilised to engage families in ECD activities; iv) multi-sectoral collaboration can be strengthened to support effective ECD delivery; and v) national ECD policies can be better translated into local priorities with a clearer set of activities and support.

Throughout this study, and from varied respondents, the VHTs were identified as ideal change agents. Across respondent groups, VHTs were felt to provide reliable information and advice. Carers feel confident in their advice and already seek their counsel and services. We propose that this existing cadre of workers might be mobilised to implement community-based, ECD-focused interventions that are embedded within existing systems and would therefore require little or no further staffing to take to scale. The important role of community health workers broadly (Kok et al. 2017) and Ugandan VHTs (Babughirana et al. 2016, Musinguzi et al. 2017, Turinawe et al. 2015) as resident advocates for positive local change has been recognised in the literature. Advocating additional responsibilities for VHTs will require consideration of the need for community and governmental support to maintain and optimise their performance that has also been commonly noted (Kok et al. 2015, Mays et al. 2017, MoH 2010b). The findings of this study suggest that such strategies may also be complemented by the support of local community-based opinion leaders, such as imams, priests and nurses. Mobilising opinion leaders also recognises that the achievement of improved child development outcomes requires support from parents, families and their wider communities; otherwise known as nurturing environments (Britto et al. 2018). Finally, on the basis of these findings, and supported by other published evidence (Aboud et al. 2018), we propose a greater focus on the role of fathers in ECD and advocate for their formal inclusion in any future ECD activities in the Ugandan context.

\subsection{Study limitations}

While the design of this study took steps to counter the risks of social desirability bias influencing the results, we cannot be sure they were completely effective. Fieldworkers fluent in the local language were recruited and trained over a week in the study purpose 
and design. Daily debriefings were held where methodological challenges were discussed and data interpretations were challenged and validated. Despite these mitigating strategies, some respondent testimony may have been led. We needed to explore key areas of content and by introducing them we may have indicated their importance and cannot be sure respondents did not produce testimony they felt may please the researchers. In particular, we recognise that there is currently no language for-or clear understanding of - child stimulation and cognition at the family level. While we explored this area within this study, the terms used may have been inappropriate. This area in particular warrants further enquiry to develop a more nuanced understanding of appropriate terminology. We also recognise that exploring the question of how these results occurred in the context may benefit from ethnographic studies to explore local parenting practices and critical studies to explore in greater depth the political and economic conditions in which parenting occurs in Luuka.

\section{CONCLUSION}

This study sought to generate evidence to support the development of a scalable ECD programme in Uganda. It did this by exploring current ECD policy and programming, political and community will to support ECD activities and the opportunities for, and likely challenges to, the expansion of ECD activities in this context. This study also explored carer and community notions of child development and aspirations for the development of children.

We find that there is strong political and community support for ECD programming in Uganda, although that agenda is currently synonymous with child growth and nutrition. Shifting the discourse from 'survive' to 'thrive', and challenging views that: intelligence is innate, corporal punishment is positive and compliant children desirable, will require the shifting of social norms at a wider community level. Existing community and health system (VHTs) structures are potentially already in place to implement a community-based approach. The findings presented here appear to support a strategy based on challenging and influencing social norms around parenting practice to achieve saturation; the Saturation++ approach. On the basis of the evidence presented in this paper, we argue this can be achieved at community level through peer influence, the mobilisation of opinion leaders, engaging VHTs as change agents and garnering the support of community leaders. 


\section{REFERENCES}

Aboud, F. E., Yousafzai, A. K. \& Nores, M. (2018), 'State of the Science on Implementation Research in Early Child Development and Future Directions', Annals of the New York Academy of Sciences, 1419: 264-71. https://doi.org/10.1111/nyas. 13722

Babughirana, G., Lorna, M. \& Kimurahebwe, C. (2016), 'Village Health Team Functionality in Uganda: Implications for Community System Effectiveness', Science Journal of Public Health, 4: 117-26. https://doi.org/10.11648/j.sjph.20160402.16

Bandura, A. (2001), 'Social Cognitive Theory: An Agentic Perspective', Annual Review of Psychology, 52: 1-26. https://doi.org/10.1146/annurev.psych.52.1.1

Black, M. M., Walker, S. P., Fernald, L. C., Andersen, C. T., Digirolamo, A. M., Lu, C., Mccoy, D. C., Fink, G., Shawar, Y. R. \& Shiffman, J. (2017), 'Early Childhood Development Coming of Age: Science Through the Life Course', The Lancet, 389: 77-90. https://doi.org/10.1016/S0140-6736(16)31389-7

Boivin, M. J., Bangirana, P., Nakasujja, N., Page, C. F., Shohet, C., Givon, D., Bass, J. K., Opoka, R. O. \& Klein, P. S. (2013), 'A Year-long Caregiver Training Program Improves Cognition In Preschool Ugandan Children With Human Immunodeficiency Virus', The Journal of Pediatrics, 163: 140916. e5. https://doi.org/10.1016/j.jpeds.2013.06.055

Boivin, M. J., Nakasujja, N., Familiar-Lopez, I., Murray, S. M., Sikorskii, A., Awadu, J., Shohet, C., Givon, D., Ruiseñor-Escudero, H. \& Schut, E. E. (2017), 'Effect of Caregiver Training on the Neurodevelopment of HIV-exposed Uninfected Children and Caregiver Mental Health: A Ugandan Cluster-randomized Controlled Trial', Journal of Developmental and Behavioral Pediatrics: JDBP, 38: 753-64. https://doi.org/10.1097/DBP.0000000000000510

Braun, V. \& Clarke, V. (2006), 'Using Thematic Analysis in Psychology', Qualitative Research in Psychology, 3: 77-101. https://doi.org/10.1191/1478088706qp063oa

Britto, P. R., Engle, P. \& Alderman, H. (2013), 'Early Intervention and Caregiving: Evidence from the Uganda Nutrition and Early Child Development Program' Child Health Education, 1: 112-33.

Britto, P. R., Singh, M., Dua, T., Kaur, R. \& Yousafzai, A. K. (2018), 'What Implementation Evidence Matters: Scaling-up Nurturing Interventions that Promote Early Childhood Development', Annals of the New York Academy of Sciences, 1419: 5-16. https://doi.org/10.1111/nyas.13720

Campbell, F., Conti, G., Heckman, J. J., Moon, S. H., Pinto, R., Pungello, E. \& Pan, Y. (2014), 'Early Childhood Investments Substantially Boost Adult Health', Science, 343: 1478-85. https://doi.org/10.1126/science.1248429

Chan, M. (2013), 'Linking Child Survival and Child Development for Health, Equity, and Sustainable Development', The Lancet, 381: 1514-15. https://doi.org/10.1016/S0140-6736(13)60944-7

Chung, A. \& Rimal, R. N. (2016), 'Social Norms: A Review', Review of Communication Research, 4: $1-28$.

CIA (2017), The World Factbook Central Intelligence Agency.

https://www.cia.gov/library/publications/the-world-factbook/rankorder/2127rank.html

Gertler, P., Heckman, J., Pinto, R., Zanolini, A., Vermeersch, C., Walker, S., Chang, S. M. \& GranthamMcgregor, S. (2014), 'Labor Market Returns to an Early Childhood Stimulation Intervention in Jamaica', Science, 344: 998-1001. https://doi.org/10.1126/science.1251178

Grantham-Mcgregor, S., Cheung, Y. B., Cueto, S., Glewwe, P., Richter, L., Strupp, B. \& Group, I. C. D. S. (2007), 'Developmental Potential in the First 5 Years for Children in Developing Countries', The Lancet, 369: 60-70. https://doi.org/10.1016/S0140-6736(07)60032-4

Grantham-Mcgregor, S. M., Fernald, L. C., Kagawa, R. \& Walker, S. (2014), 'Effects of Integrated Child Development and Nutrition Interventions on Child Development and Nutritional Status', Annals of the New York Academy of Sciences, 1308: 11-32. https://doi.org/10.1111/nyas.12284 
Haslam, S. A., Ellemers, N., Reicher, S. D., Reynolds, K. J. \& Schmitt, M. T. (2010), 'The Social Identity Perspective Today: An Overview of its Defining Ideas', in T. Postmes \& N. R. Branscombe (eds) Rediscovering Social Identity (New York, Psychology Press).

Irwin, L. G., Siddiqi, A. \& Hertzman, G. (2007), Early Child Development: A Powerful Equalizer (Vancouver, BC, Human Early Learning Partnership (HELP)).

Kok, M. C., Dieleman, M., Taegtmeyer, M., Broerse, J. E., Kane, S. S., Ormel, H., Tijm, M. M. \& De Koning, K. A. (2015), 'Which Intervention Design Factors Influence Performance of Community Health Workers in Low-and-middle-income Countries? A Systematic Review', Health Policy and Planning, 30: 1207-27. https://doi.org/10.1093/heapol/czu126

Kok, M. C., Ormel, H., Broerse, J. E., Kane, S., Namakhoma, I., Otiso, L., Sidat, M., Kea, A. Z., Taegtmeyer, M. \& Theobald, S. (2017), 'Optimising the Benefits of Community Health Workers' Unique Position Between Communities and the Health Sector: A Comparative Analysis of Factors Shaping Relationships in Four Countries', Global Public Health, 12(11): 1404-32. https://doi.org/10.1080/17441692.2016.1174722

Lake, A. (2011), 'Early Childhood Development - Global Action is Overdue', The Lancet, 378: 1277-78. https://doi.org/10.1016/S0140-6736(11)61450-5

Luby, J. L. (2015), 'Poverty's Most Insidious Damage: The Developing Brain', Jama Pediatrics, 169: 810-11. https://doi.org/10.1001/jamapediatrics.2015.1682

Manji, K. P., McDonald, C. M., Kupka, R., Bosch, R. J., Kisenge, R., Aboud, S., Bellinger, D. C., Fawzi, W. W. \& Duggan, C. P. (2014), 'Effect of Multivitamin Supplementation on the Neurodevelopment of HIV-exposed Tanzanian Infants: A Randomized, Double-blind, Placebo-controlled Clinical Trial', Journal of Tropical Pediatrics, 60: 279-86. https://doi.org/10.1093/tropej/fmu011

Mays, D. C., O’Neil, E. J., Mworozi, E. A., Lough, B. J., Tabb, Z. J., Whitlock, A. E., Mutimba, E. M. \& Talib, Z. M. (2017), 'Supporting and Retaining Village Health Teams: An Assessment of a Community Health Worker Program in Two Ugandan Districts', International Journal for Equity in Health, 16: 129. https://doi.org/10.1186/s12939-017-0619-6

MOES (2010), The Uganda Education Sector Strategic Plan 2004-2015 (Kampala, Ministry of Education and Sports).

MoGLSD (2016a), The National Integrated Early Child Development Policy of Uganda (Kampala, The Ugandan Ministry of Gender, Labour and Social Development).

MoGLSD (2016b), The National Integrated Early Childhood Development Policy Action Plan of Uganda (2016-2021) (Kampala, Ugandan Ministry of Gender Labour and Social Development).

MOH (2010a), 'Ministry of Health Policy and Guideline on How to Engage and Utilize Village Health Teams in Community-based Health Services Delivery in Uganda' (Kampala. The Republic of Uganda Ministry of Health).

MOH (2010b), 'Ministry of Health Policy and Guideline on How to Engage and Utilize Village Health Teams in Community-based Health Services Delivery in Uganda' (Kampala, The Republic of Uganda Ministry of Health).

Morris, J., Jones, L., Berrino, A., Jordans, M. J., Okema, L. \& Crow, C. (2012), 'Does Combining Infant Stimulation With Emergency Feeding Improve Psychosocial Outcomes for Displaced Mothers and Babies? A Controlled Evaluation from Northern Uganda', American Journal of Orthopsychiatry, 82: 349-57. https://doi.org/10.1111/j.1939-0025.2012.01168.x

Muhoozi, G. K., Atukunda, P., Mwadime, R., Iversen, P. O. \& Westerberg, A. C. (2016), 'Nutritional and Developmental Status Among 6-to 8-Month-old Children in Southwestern Uganda: A Crosssectional Study', Food and Nutrition Research, 60: 30270. https://doi.org/10.3402/fnr.v60.30270

Muhoozi, G. K., Atukunda, P., Diep, L. M., Mwadime, R., Kaaya, A. N., Skaare, A. B., Willumsen, T., Westerberg, A. C. \& Iversen, P. O. (2018), 'Nutrition, Hygiene, and Stimulation Education to Improve Growth, Cognitive, Language, and Motor Development Among Infants in Uganda: A Cluster-randomized Trial', Maternal and Child Nutrition, 14(2): e12527.

https://doi.org/10.1111/men.12527 
Murray, J., Remes, P., Ilboudo, R., Belem, M., Salouka, S., Snell, W., Wood, C., Lavoie, M., Deboise, L. \& Head, R. (2015), 'The Saturation+ Approach to Behavior Change: Case Study of a Child Survival Radio Campaign in Burkina Faso', Global Health: Science and Practice, 3: 544-56. https://doi.org/10.9745/GHSP-D-15-00049

Musinguzi, L. K., Turinawe, E. B., Rwemisisi, J. T., De Vries, D. H., Mafigiri, D. K., Muhangi, D., De Groot, M., Katamba, A. \& Pool, R. (2017), 'Linking Communities to Formal Health Care Providers Through Village Health Teams in Rural Uganda: Lessons from Linking Social Capital', Human Resources for Health, 15(1): 4. https://doi.org/10.1186/s12960-016-0177-9

Noble, K. G., Houston, S. M., Brito, N. H., Bartsch, H., Kan, E., Kuperman, J. M., Akshoomoff, N., Amaral, D. G., Bloss, C. S. \& Libiger, O. (2015), 'Family Income, Parental Education and Brain Structure in Children and Adolescents', Nature Neuroscience, 18(5): 773-8. https://doi.org/10.1038/nn.3983

Postmes, T. \& Branscombe, N. R. (2010), Rediscovering Social Identity (New York, Psychology Press).

Prado, E. L., Abbeddou, S., Adu-Afarwuah, S., Arimond, M., Ashorn, P., Ashorn, U., Bendabenda, J., Brown, K. H., Hess, S. Y. \& Kortekangas, E. (2017), 'Predictors and Pathways of Language and Motor Development in Four Prospective Cohorts of Young Children in Ghana, Malawi, and Burkina Faso', Journal of Child Psychology and Psychiatry, 58: 1264-275. https://doi.org/10.1111/jepp.12751

Rockers, P. C., Zanolini, A., Banda, B., Chipili, M. M., Hughes, R. C., Hamer, D. H. \& Fink, G. (2018), 'Two-year Impact of Community-based Health Screening and Parenting Groups on Child Development in Zambia: Follow-up to a Cluster-randomized Controlled Trial', PLoS Medicine, 15: e1002555. https://doi.org/10.1371/journal.pmed.1002555

Rubio-Codina, M., Araujo, M. C., Attanasio, O., Muñoz, P. \& Grantham-Mcgregor, S. (2016), 'Concurrent Validity and Feasibility of Short Tests Currently Used to Measure Early Childhood Development in Large Scale Studies', PLoS One, 11: e0160962.

https://doi.org/10.1371/journal.pone.0160962

Schady, N. (2015), The Early Years: Child Well-being and the Role of Public Policy (New York, Springer). https://doi.org/10.18235/0000186

Shonkoff, J. P., Garner, A. S. et al. (2012), 'The Lifelong Effects of Early Childhood Adversity and Toxic Stress', Pediatrics, 129: e232-46. https://doi.org/10.1542/peds.2011-2663

Singla, D. R., Kumbakumba, E. \& Aboud, F. E. (2015), 'Effects of a Parenting Intervention to Address Maternal Psychological Wellbeing and Child Development and Growth in Rural Uganda: A Community-based, Cluster-randomised Trial', The Lancet Global Health, 3: e458-69. https://doi.org/10.1016/S2214-109X(15)00099-6

Stewart, C. P., Kariger, P., Fernald, L., Pickering, A. J., Arnold, C. D., Arnold, B. F., Hubbard, A. E., Dentz, H. N., Lin, A. \& Meerkerk, T. J. (2018), 'Effects of Water Quality, Sanitation, Handwashing, and Nutritional Interventions on Child Development in Rural Kenya (Wash Benefits Kenya): A Cluster-randomised Controlled Trial', The Lancet Child and Adolescent Health, 2: 269-80. https://doi.org/10.1016/S2352-4642(18)30025-7

Turinawe, E. B., Rwemisisi, J. T., Musinguzi, L. K., De Groot, M., Muhangi, D., De Vries, D. H., Mafigiri, D. K. \& Pool, R. (2015), 'Selection and Performance of Village Health Teams (VHTs) in Uganda: Lessons from the Natural Helper Model of Health Promotion', Human Resources For Health, 13: 73. https://doi.org/10.1186/s12960-015-0074-7

UBoS (2016), 'The National Population and Housing Census 2014-Main Report' (Kampala, Uganda Bureau of Statistics).

UBoS (2018), 'Uganda National Household Survey 2016/17' (Kampala, Uganda Bureau of Statistics).

UBoS \& ICF (2017), 'Uganda Demographic and Health Survey 2016: Key Indicators Report' (Kampala, Uganda Bureau of Sataistics, and Rockville, MD, ICF).

United Nations (1989), United Nations Convention on the Rights of the Child. 
United Nations (2006), Convention on the Rights of Persons with Disabilities, General Assembly Resolution 61/106.

Walker, S. P., Chang, S. M., Vera-Hernández, M. \& Grantham-Mcgregor, S. (2011), 'Early Childhood Stimulation Benefits Adult Competence and Reduces Violent Behavior', Pediatrics, 27(5): 849-57. https://doi.org/10.1542/peds.2010-2231

Wallander, J. L., Biasini, F. J., Thorsten, V., Dhaded, S. M., De Jong, D. M., Chomba, E., Pasha, O., Goudar, S., Wallace, D. \& Chakraborty, H. (2014), 'Dose of Early Intervention Treatment During Children's First 36 Months if Life is Associated With Developmental Outcomes: An Observational Cohort Study in Three Low/Low-Middle Income Countries', BMC Pediatrics, 14: 281. https://doi.org/10.1186/1471-2431-14-281

Weaver, I. C. (2014), 'Integrating Early Life Experience, Gene Expression, Brain Development, and Emergent Phenotypes: Unraveling the Thread of Nature Via Nurture', Advances In Genetics, 86: 277-307https://doi.org/10.1016/B978-0-12-800222-3.00011-5

WHO (2012), 'Care for Child Development: Improving the Care of Young Children' (Geneva, World Health Organization).

Worku, B. N., Abessa, T. G., Wondafrash, M., Lemmens, J., Valy, J., Bruckers, L., Kolsteren, P. \& Granitzer, M. (2018), 'Effects of Home-based Play-assisted Stimulation on Developmental Performances of Children Living in Extreme Poverty: A Randomized Single-blind Controlled Trial', BMC Pediatrics, 18: 29. https://doi.org/10.1186/s12887-018-1023-0

World Bank (2017), 'The World Bank in Uganda', The World Bank Group. http://www.worldbank.org/ en/country/uganda

World Bank (2018), 'Fertility Rate, Total (Births Per Woman): Uganda', The World Bank. https://data.worldbank.org/indicator/SP.DYN.TFRT.IN?locations=UG

Yousafzai, A. K., Aboud, F. E., Nores, M. \& Kaur, R. (2018), 'Reporting Guidelines for Implementation Research on Nurturing Care Interventions Designed to Promote Early Childhood Development', Annals of the New York Academy of Science, 1419: 26-37. https://doi.org/10.1111/nyas.13648

\section{Notes on the authors}

Jolene Skordis is an economist specialising in the Economics of Health and Development. Professor Skordis works within randomised trials of complex behavioural and public health interventions. Together with colleagues and communities, she has developed new survey tools to measure poverty, capability and gender empowerment, health worker satisfaction and health worker motivation. This work has led to a new understanding of how money is shared within households and how younger women are disadvantaged; a new theory linking social networks to health behaviour and outcomes in South East Asia; a new measure of human capabilities which could be used to measure the broader impact of multisectoral interventions; and she has expanded our understanding of the way in which health workers respond to financial and non-financial incentives. She is Deputy Director of UCL's Institute for Global Health, Director of UCL's Centre for Global Health Economics and a Senior Research Fellow at the Institute for the Future of Work.

j.skordis@ucl.ac.uk

Daniel Strachan is a Senior Research Associate at the UCL Institute for Global Health. He is a social scientist by training, and in recent years his work has focused on 
community health workers and their performance motivation in Uganda. Recently Daniel's research focus has returned to early child development through a British Academy Grant in Uganda in collaboration with colleagues at IGH's Centre for Global Health Economics. This is a long-standing area of research interest, with Daniel having formerly worked in early child development policy and service development and evaluation primarily in hard-to-reach Australian communities. He was also involved in the development of an online parenting resource in Australia, the Raising Children Network (http://www.raisingchildren.net.au). Now based in London, Daniel has worked in the UK, across East Africa and in Australia with a focus on communities and health systems that support improving health and developmental outcomes.

Peter Waiswa is the Principal Investigator, Makerere University, Uganda. Professor Waiswa is a Ugandan medical doctor and health systems researcher with particular focus on newborn health and development and maternal-newborn-child health services. He leads the InDepth network on Maternal-Newborn health and is a frequent advisor to international organisations on perinatal-newborn health. With a background in district health service provision in rural Uganda, he holds a joint $\mathrm{PhD}$ degree from Karolinska Institutet and Makerere University, and is on the faculty at Makerere University School of Public Health, Uganda, as well as at Karolinska Institutet, Sweden.

Hassan Haghparast-Bidgoli is the Deputy Director of UCL's Centre for Global Health Economics and an Associate Professor of Health Economics at UCL. His primary area of work is in the analysis of inequalities in health and (access and utilisation of) health care, and economic evaluation of health care interventions. He also has interests in injury prevention and trauma care. Hassan is currently involved in economic analysis of trials in South-East Asia and Sub-Saharan Africa, focusing on maternal and child health, child malnutrition and sexual reproductive health.

To cite the article: Daniel Strachan, Lydia Kabwijamu, Monica Okuga, Callie DanielsHowell, Hassan Haghparast-Bedgoli, Rebecca Nantanda, Jolene Skordis and Peter Waiswa (2019), 'Shifting the discourse from survive to thrive: a qualitative exploration of beliefs, actions and priorities for early child development in Uganda', Journal of the British Academy, 8(s2): 41-70.

DOI https://doi.org/10.5871/jba/008s2.041

Journal of the British Academy (ISSN 2052-7217) is published by

The British Academy, 10-11 Carlton House Terrace, London, SW1Y 5AH

www.thebritishacademy.ac.uk 